\title{
Tobacco promotion 'below-the-line': Exposure among adolescents and young adults in NSW, Australia
}

\author{
Donna A Perez ${ }^{1}$, Anne C Grunseit ${ }^{2}$, Chris Rissel ${ }^{2}$, James Kite ${ }^{* *}$, Trish Cotter ${ }^{1}$, Sally Dunlop ${ }^{1,2}$ and Adrian Bauman²
}

\begin{abstract} Background

Exposure to tobacco advertising and promotion increases the likelihood of smoking amongst young people. While there is a universal ban on traditional or 'above-the-line' advertising in Australia, the types and extent of exposure of young people to 'below-the-line' tobacco advertising and promotion is largely unknown. In this study we aim to identify levels of exposure of New South Wales (NSW) adolescents and young adults to tobacco promotion at the point-of-sale (PoS), on the internet, in entertainment media and at venues such as events or festivals and pubs, clubs, nightclubs, or bars; and to identify those most at risk of exposure.
\end{abstract}

\section{Methods}

A telephone survey of $1000 \mathrm{NSW}$ adolescents and young adults aged 12 to 24 years was conducted. Self-reported exposure to tobacco promotions or advertising in the last month were measured in four areas: (1) promotions or advertising at (a) events or festivals and (b) pubs, clubs, nightclubs or bars, (2) on the internet, (3) people smoking cigarettes in (a) movies, (b) TV shows, (c) video games and (d) on the internet, and (4) displays of cigarette packs for sale at (a) large supermarkets, (b) grocery stores or small supermarkets, (c) convenience stores, and (d) service or petrol stations. Smoking status and susceptibility to smoking was also assessed.

\section{Results}

A substantial proportion of the young people surveyed reported seeing tobacco promotion sometimes or often in the last month over most of the channels studied. The highest levels of exposure were at the PoS (approx. two-thirds) and to people smoking cigarettes in movies

\footnotetext{
* Correspondence: james.kite@cancerinstitute.org.au

'Cancer Institute NSW, Eveleigh, New South Wales, Australia

Full list of author information is available at the end of the article
}

(77\%). Lower levels of exposure to tobacco promotions and imagery were reported on the internet (20\%); at events or festivals (22.5\%); in pubs, clubs, nightclubs or bars (31\%); and in video games (23\%). However, the odds of exposure through video games increased by $8 \%$ for every additional hour spent on the internet per day.

\section{Conclusions}

This study shows that adolescents and young adults in NSW are exposed to tobacco advertising or promotion at the PoS, on the internet, in entertainment media and at venues such as events or festivals and pubs, clubs, nightclubs or bars, despite the restrictions on the marketing of tobacco in Australia.

\section{Background}

There is considerable evidence linking exposure to tobacco advertising and promotion with an increased likelihood of smoking amongst young people.[1-4] As a result, an increasing number of countries have implemented bans on tobacco advertising, marketing and promotion.[5] Australia's Tobacco Advertising Prohibition Act 1992 and tobacco control legislation in the states and territories has been implemented to prevent most promotion or marketing of tobacco through traditional or 'above-the-line' forms of media (print, radio, television, billboards, and other locations) [6,7].

In New South Wales (NSW), the most populous state of Australia, the Public Health (Tobacco) Act of 2008 introduced new requirements relating to advertising of tobacco products on retail premises, including how tobacco products may be displayed. The new regulations state that tobacco products must be stored out of sight so that they cannot be seen by the public from inside or outside the retail premises. Large retailers (more than 50 employees) went out of sight 1 January 2010 (Phase 1 ), small retailers (50 or fewer employees) followed from 
1 July 2010 (Phase 2) and specialist tobacconists must comply by 1 January 2013 (Phase 3 ).

Despite the ban on most traditional forms of tobacco advertising and promotion in Australia, the tobacco industry has adapted by diverting resources to non-traditional or 'below-the-line' means of promotion, such as point-of-sale (PoS) displays; portrayal in films or movies; TV programs, magazines and electronic games; internet advertising and events marketing.[7-10]

Large-scale population studies have shown that greater exposure to PoS tobacco displays is associated with an increased likelihood of adolescent smoking.[11-17] A recent study in the United Kingdom (UK), for instance, found that both noticing and being attracted to PoS displays were associated with susceptibility to smoking amongst never smokers aged 11 to 16 years.[18] Furthermore, experimental studies have shown that youth exposed to images of tobacco-saturated PoS displays had stronger perceptions relating to the availability and ease of tobacco purchase and of peer and adult smoking as well as less support for tobacco control policies, compared to youth exposed to images of PoS displays with no tobacco imagery.[19,20]

The appearance of tobacco brands or tobacco related products in cinema films has a long history and is a pervasive form of tobacco promotion.[21] A recent study from the UK showed that tobacco appeared in $70 \%$ of the most popular films from 1989 to 2008.[22] A number of studies have shown that greater exposure to smoking in films is associated with an increased likelihood of smoking among adolescents and young adults [23-29], and that this transcends different cultural contexts.[30] Evidence as to the extent and effects of youth exposure to media portrayals of smoking has previously come from countries such as the United States (US) and the UK, however, with little research to date on the level and effect of exposure in Australian youth.

The internet may also influence youth tobacco use because it provides potential access to tobacco products, as well as a venue that may stimulate demand through advertising and promotional messages.[31] In 2005, almost one fifth of adult internet users in the US recalled seeing tobacco products advertised online, with young adults being the most likely group to recall such advertising.[32] Newly emerging forms of marketing include viral marketing through social networking sites in which tobacco company names, logos and images can be prominently displayed and rapidly disseminated amongst users of the sites.[33] This type of marketing, though aimed primarily at young adults, is also likely to influence younger teenagers.[6]

Research investigating online exposure to tobacco promotion has largely focused on adults [32], with little or no research to date focusing on adolescent exposure, despite the wide-spread use of the internet in this age group.[33]

It is important to assess exposure among adolescents and young adults to non-traditional or below-the-line means of tobacco promotion, given this may be undermining tobacco control efforts and diminishing the potential to further prevent uptake or reduce smoking in this group of young people.

This study aims to identify (1) the degree to which NSW adolescents (12-17 years of age) and young adults (18-24 years of age) have been exposed to tobacco promotion at the PoS, on the internet, in entertainment media, and at entertainment venues; and (2) to profile the characteristics of adolescents and young adults most at risk of exposure to these types of tobacco promotion.

\section{Methods \\ Design}

The Cancer Institute NSW's Tobacco Promotion Impact Study (TPIS) is a telephone survey of adolescents and young adults aged 12 to 24 years in New South Wales (NSW). It monitors exposure to tobacco promotion at the PoS, on the internet and in entertainment media, and smoking-related cognitions and behaviours. This paper presents findings from the baseline survey conducted in NSW in June 2010.

Households were recruited using random digit dialling (landline telephone numbers only) and participants within households were recruited using random selection (selecting the $n$th oldest eligible person aged 12 to 24 years). Permission was obtained from parents of 12 to 15 year olds before conducting each interview. Participants were interviewed between 8 June and 30 June $2010(n=1,000)$. The questionnaire was piloted with the survey population prior to the commencement of fieldwork. An overall response rate of $45 \%$ (using the American Association for Public Opinion Research Response Rate \#3) was achieved for this period [34], comparable or superior to other similar studies. [35,36] The TPIS was approved by the NSW Population Health Services Research Ethics Committee.

\section{Measures}

\section{Individual characteristics}

Demographic items capturing age, gender, region (Sydney vs. Rest of NSW), living arrangement, language spoken at home, and disposable income were included in the study. Postcode of residence was coded according to the Socio-Economic Indices for Areas SEIFA; [37], an index of relative disadvantage, to indicate neighbourhood socio-economic status (SES). Quintiles 4-5 were collapsed to indicate low SES, and quintiles 1-3 were collapsed to indicate moderate to high SES. Age was operationalised for the bivariate and multiple variable 
analyses as a binary variable grouping together participants aged 12-17 years (adolescents), and those aged 1824 years (young adults).

The amount of time spent on the internet and watching TV was reported as hours and minutes per day and converted to hours per day (maximum of $10 \mathrm{~h}$ ). Amount of disposable income was measured by asking participants how much money they had available during a normal week to spend on themselves (none, $\$ 50$ or less, $\$ 50-\$ 100, \$ 100-\$ 150, \$ 150-\$ 200$, over $\$ 200$, don't know). The categories were collapsed to none, $\$ 50$ or less, \$50-\$100, $\$ 100+$, unknown for analysis.

\section{Smoking status}

Current smokers were defined as those who had smoked cigarettes in the past month. Ex-smokers were those who had ever smoked cigarettes, but not in the past month, and had smoked 100 cigarettes or more in their lifetime. Experimenters had ever smoked cigarettes, but not in the past month, and had smoked less than 100 cigarettes in their lifetime. Non-smokers were categorised into one of two groups: susceptible non-smokers and non-susceptible non-smokers.[38] To determine susceptibility to smoking, participants who had never had a puff of a cigarette were asked "Do you think you will try cigarettes sometime soon", "Do you think you will try cigarettes sometime in the next year" and "If a friend offered you a cigarette, would you try it" (definitely no, probably no, probably yes, definitely yes). Susceptible non-smokers were those whose response to any one of the three smoking susceptibility items was anything other than 'definitely no'. Non-susceptible non-smokers were those who answered 'definitely no' to all three smoking susceptibility items. For the multiple variable analysis, a binary "ever smoked" variable was used with those who answered "yes" to "have you ever smoked a cigarette, even just a puff" coded as "ever smokers" and those who answered "no" or "don't know" as "never smoked".

\section{Smoking exposure}

Exposure to smoking in the household and among friends was assessed by recording the number of current smokers in a respondent's household and how many (if any) of the participants' five closest friends smoked. As both of these variables had highly skewed distributions, smoking in the household was operationalised as a three category variable (none, one person, two or more people) and smoking among friends as a four category variable (none, one friend, two friends, three or more friends).

\section{Perceived exposure to tobacco promotion}

Self-reported exposure to tobacco promotions or advertising in the last month were measured in four areas: (1) promotions or advertising at (a) events or festivals and (b) pubs, clubs, nightclubs or bars, (2) brands, company names or logos on the internet, (3) people smoking cigarettes in (a) movies, (b) TV shows, (c) video games (platform not specified) and (d) on the internet, and (4) displays of cigarette packs for sale at (a) large supermarkets (defined for participants as having more than five cash registers), (b) grocery stores or small supermarkets, (c) convenience stores, and (d) service or petrol stations. Respondents aged $12-15$ years $(n=334)$ were not asked about exposure in pubs, clubs, nightclubs or bars due to the low likelihood they would be attending these venues. Exposure to cigarette pack displays at PoS was measured as, firstly, how often the respondent visited each store type (never, rarely, sometimes, often). Those who had ever visited these stores were then asked how often they had seen displays of cigarette packs for sale in each using the same response frame.

\section{Statistical analyses}

\section{Outcome measures on exposure to tobacco promotion}

For all tobacco promotion channels except cigarette pack displays, the response categories of never/rarely and sometimes/often were collapsed to create binary exposure variables. Respondents who reported that they didn't know whether they had seen such promotions were coded "never/rarely" for exposure. Those who refused to answer a question were coded as missing for that exposure channel (at maximum $\mathrm{n}=2$ ).

Exposure to cigarette pack displays in stores (large supermarkets, small supermarkets, convenience stores and petrol stations) were combined measures reflecting both frequency of visits to the store type and the frequency with which the respondent said they saw cigarette pack displays at that store. For both visit frequency and frequency of seeing pack displays, the coding ranged from 0 (never) to 3 (often). For each store type, the two frequency variables were multiplied to create a combined numeric cigarette pack display exposure score which was subsequently categorised as follows: Low exposure: participants who reported they either never visited that store type or never saw cigarette pack displays (irrespective of store visit frequency) or rarely visited and rarely saw pack displays (score 0 or 1); High exposure: combinations of visit frequency and seeing cigarette pack display frequency of either often and sometimes, or often and often (score 6 or 9); and Medium exposure: all other combinations of store visit and frequency of seeing pack displays (score 2 to 4). For the multiple variable analysis, the outcome variable for exposure to cigarette pack displays in stores was a single binary variable coded high exposure (versus not high) for the exposure score (as calculated above) aggregated over all store types. High exposure was defined as being in the top quartile of the total exposure score. 


\section{Analytic techniques}

Descriptive statistics were generated for the tobacco promotion channels by gender and age group (12-17 and 18-24 years). Bivariate comparisons of level of exposure over all promotion channels across gender and age were examined using chi-square.

Multiple logistic regression models estimated the adjusted odds of participants reporting seeing each of the different types of tobacco promotion sometimes or often. Each model included as predictors: age group (1217 years, 18-24 years), gender, SES (advantaged, disadvantaged), disposable income, ever smoked, household smokers, and friends smoking. For outcome variables examining tobacco promotion on the internet and in video games, hours per day spent on the internet was also included in the model, and the model examining depiction of people smoking in TV shows also included time spent watching TV (in hours per day). Contrasts with the reference category for multiple category predictor variables were Bonferroni adjusted.

The data were weighted to the NSW population for known age (12-15 years, 16-19 years, 20-24 years), sex (female, male) and region (Sydney, Rest of state) distributions for 12-24 year olds within NSW from the 2006 Australian Bureau of Statistics (ABS) Census data [39] using post-stratification weights. All analyses were conducted using Stata v11.1 [40] and used a threshold of alpha at 0.05 for statistical significance.

\section{Results}

\section{Description of sample}

Table 1 shows the (unweighted) socio-demographic characteristics of the sample of participants from NSW $(\mathrm{n}=1000)$, by age group.

Just under half the sample were male and were aged 18-24 years. Almost one-third lived in areas categorised as disadvantaged by SEIFA index. The majority of participants lived with their parents or guardians, although one-sixth of young adults (18-24 years) lived away from their parents. Most participants were not currently smoking (83\%), and reported that no one in their household (67\%) smoked, however just over half had friends who smoked. Just under two-thirds of participants aged 12-17 years had less than $\$ 50$ in disposable income per week, while the same proportion of young adults had $\$ 100$ or more for discretionary spending. Median internet use and time spent watching TV was two hours and $1.5 \mathrm{~h}$ per day respectively and was the same for both the adolescents and young adults.

\section{Bivariate analyses of tobacco promotion}

The proportion of participants reporting having seen tobacco promotion in the past month and results of the bivariate comparisons of tobacco promotion exposure across age group and gender are shown in Table 2.

Overall, a substantial proportion of the young people surveyed reported seeing tobacco promotion sometimes or often in the last month over most of the channels. The highest rate was for seeing people smoking in movies (77\%) and the lowest was for seeing tobacco brands, company names or logos on the internet (20\%). Around one-third each reported seeing cigarette pack displays in low, medium, or high frequency and this distribution was similar across the different store types (large and small supermarkets, convenience stores and petrol stations).

Bivariate analyses of reported tobacco promotion exposure for the different channels by gender showed few differences except more male participants saw people smoking sometimes/often in video games $(33 \%$ vs. $13 \%, p<0.001)$ than females, while female participants reported seeing cigarette pack displays at high frequency in large supermarkets, small supermarkets and convenience stores more often than males.

Comparisons of exposure to tobacco promotion by age showed adolescents were more likely than the young adults to report seeing brands, company names or logos on the internet, promotions/advertising at events/festivals, and cigarette pack displays in large and small supermarkets, but had lower exposure to promotions/advertising at pubs/clubs/nightclubs/bars (16-17 year olds only). Young adults reported higher levels of exposure to cigarette pack displays in petrol stations. No differences by age were observed for seeing people smoking cigarettes in movies, on TV shows, in video games or on the internet.

\section{Multiple variable analyses of tobacco promotion}

Table 3 shows results of the significant adjusted models of exposure to tobacco promotion at events/festivals, on the internet, in video games and cigarette pack displays in all stores combined.

Overall models for exposure to promotion/advertising in pubs/clubs/nightclubs/bars, seeing people smoking cigarettes in movies, in TV shows or on the internet did not reach statistical significance and therefore are not further described.

For tobacco promotion/advertising at events/festivals, only the number of friends who smoked was significantly related to seeing this type of promotion once adjusted for all other variables. Those with one smoking friend compared with no friends who smoked had almost twice the odds of reporting seeing this type of promotion sometimes or often.

The odds of seeing cigarette brands, tobacco company names or logos on the internet were more than halved 
Table 1 Socio-demographic characteristics NSW sample $(n=1000)$ by age group

\begin{tabular}{|c|c|c|c|c|c|}
\hline \multirow{2}{*}{$\begin{array}{l}\text { CHARACTERISTIC } \\
\text { GENDER }\end{array}$} & \multicolumn{2}{|c|}{$\begin{array}{c}12-17 \text { years } \\
\mathrm{n}=518\end{array}$} & \multicolumn{2}{|c|}{$\begin{array}{c}18-24 \text { years } \\
n=482\end{array}$} & \multirow{2}{*}{$\begin{array}{c}\text { Total } \\
\%\end{array}$} \\
\hline & $\mathrm{n}$ & $\%$ & $\mathrm{n}$ & $\%$ & \\
\hline Male & 258 & 49.8 & 240 & 49.8 & 49.8 \\
\hline \multicolumn{6}{|l|}{ REGION } \\
\hline Sydney & 298 & 57.5 & 343 & 71.2 & 64.1 \\
\hline Rest of NSW & 220 & 42.5 & 139 & 28.8 & 35.9 \\
\hline \multicolumn{6}{|l|}{ NEIGHBOURHOOD SES } \\
\hline Low & 163 & 31.5 & 148 & 30.7 & 31.1 \\
\hline Mod-High & 355 & 68.5 & 334 & 69.3 & 68.9 \\
\hline \multicolumn{6}{|l|}{ LIVING ARRANGEMENT } \\
\hline Live with parent(s)/guardians/family & 511 & 98.8 & 402 & 83.8 & 91.6 \\
\hline Live with $\mathrm{a}$, or am sole parent/share with & 6 & 1.2 & 78 & 16.25 & 8.4 \\
\hline \multicolumn{6}{|l|}{ others/spouse/live alone } \\
\hline \multicolumn{6}{|l|}{ LANGUAGE AT HOME } \\
\hline English & 435 & 84.0 & 348 & 72.2 & 78.3 \\
\hline \multicolumn{6}{|l|}{ SMOKING STATUS } \\
\hline Current smoker & 44 & 8.5 & 125 & 25.9 & 16.9 \\
\hline Non-susceptible non-smoker & 322 & 62.2 & 155 & 32.2 & 47.7 \\
\hline Susceptible non-smoker & 84 & 16.2 & 23 & 4.8 & 10.7 \\
\hline Ex-smoker & 1 & 0.2 & 23 & 4.8 & 2.4 \\
\hline Experimenter & 67 & 12.9 & 156 & 32.4 & 22.3 \\
\hline \multicolumn{6}{|l|}{ FRIENDS SMOKING $†$} \\
\hline None & 331 & 63.9 & 149 & 30.9 & 48.0 \\
\hline 1 friend & 73 & 14.1 & 101 & 21.0 & 17.4 \\
\hline 2 friends & 55 & 10.6 & 81 & 16.8 & 13.6 \\
\hline $3+$ friends & 59 & 11.4 & 151 & 31.3 & 21.0 \\
\hline \multicolumn{6}{|l|}{ HOUSEHOLD SMOKING } \\
\hline No one & 380 & 73.4 & 285 & 59.1 & 66.5 \\
\hline 1 person & 96 & 18.5 & 133 & 27.6 & 22.9 \\
\hline $2+$ people & 42 & 8.1 & 64 & 13.3 & 10.6 \\
\hline \multicolumn{6}{|l|}{ DISPOSABLE INCOME } \\
\hline None & 51 & 9.9 & 9 & 1.9 & 6 \\
\hline$<=\$ 50$ & 332 & 64.1 & 76 & 15.8 & 40.8 \\
\hline$\$ 50-\$ 100$ & 68 & 13.1 & 70 & 14.5 & 13.8 \\
\hline$\$ 100+$ & 48 & 9.3 & 310 & 64.3 & 35.8 \\
\hline Unknown & 19 & 3.7 & 17 & 3.5 & 3.6 \\
\hline INTERNET USE* $(n=991)$ & median & mean & median & mean & Mean \\
\hline (minutes per day) & 120 & 120.5 & 120 & 171.8 & 148.1 \\
\hline \multicolumn{6}{|l|}{ TV USE* } \\
\hline (minutes per day) & 90 & 108.8 & 90 & 103.6 & 106.0 \\
\hline \multicolumn{6}{|l|}{ TV USE* } \\
\hline (minutes per day) & 90 & 108.8 & 90 & 103.6 & 106.0 \\
\hline
\end{tabular}

* Internet and TV mean use in minutes weighted to state population by age and gender.Values exceeding $600 \mathrm{~min}$ (10 $\mathrm{h},<1 \%$ of sample) recoded to 600 . † How many of five closest friends smoke.

among participants aged 18-24 years compared with adolescents, and those who had ever smoked had odds of reporting seeing this type of promotion around onethird lower than those who had never smoked.

The odds of reporting seeing people smoking cigarettes in video games sometimes or often were over $70 \%$ lower for female participants. Odds of exposure through video games also increased by $8 \%$ for every additional hour spent on the internet per day.

High exposure to cigarette pack displays was more likely for female compared with male participants (Adjusted Odds Ratio (AOR) $=1.58, p=.003$ ), but less likely for participants aged 18-24 years than those aged $12-17$ years $(\mathrm{AOR}=.61, p=.016)$. 
Table 2 Proportions in NSW exposed to forms of tobacco promotion by gender and age $(\mathbf{n}=1000)$

\begin{tabular}{|c|c|c|c|c|c|c|}
\hline EXPOSURE & Male \% & Female $\%$ & $p$ & $12-18$ years $\%$ & $18-24$ years $\%$ & Total $p$ \\
\hline \multicolumn{7}{|c|}{ PROMOTIONS OR ADVERTISING } \\
\hline Events/festivals & & & NS & & & $=.001$ \\
\hline Never/rarely & 79.7 & 75.2 & & 72.8 & 81.6 & 77.5 \\
\hline Sometimes/often & 20.3 & 27.8 & & 27.2 & 18.4 & 22.5 \\
\hline Pubs/clubs/nightclubs/bars* & & & NS & & & $=.033$ \\
\hline Never/rarely & 71.4 & 67.2 & & 75.9 & 67.3 & 69.2 \\
\hline Sometimes/often & 28.9 & 32.8 & & 24.1 & 33.7 & 30.8 \\
\hline \multicolumn{7}{|c|}{ BRANDS, COMPANY NAMES OR LOGOS } \\
\hline Internet & & & NS & & & $<.001$ \\
\hline Never/rarely & 81.9 & 78.2 & & 73.9 & 85.5 & 80.1 \\
\hline Sometimes/often & 18.1 & 21.8 & & 26.1 & 14.5 & 19.9 \\
\hline \multicolumn{7}{|l|}{ PEOPLE SMOKING CIGARETTES } \\
\hline Movies & & & NS & & & NS \\
\hline Never/rarely & 24.1 & 21.5 & & 22.6 & 23.0 & 22.8 \\
\hline Sometimes/often & 75.9 & 78.5 & & 77.4 & 77.0 & 77.2 \\
\hline TV shows & & & NS & & & NS \\
\hline Never/rarely & 34.6 & 29.3 & & 29.2 & 34.4 & 32.0 \\
\hline Sometimes/often & 65.4 & 70.7 & & 70.8 & 65.6 & 68.0 \\
\hline Video games & & & $<.001$ & & & NS \\
\hline Never/rarely & 66.7 & 87.2 & & 76.5 & 77.0 & 76.8 \\
\hline Sometimes/often & 33.3 & 12.8 & & 23.6 & 23.0 & 23.3 \\
\hline On the internet & & & NS & & & NS \\
\hline Never/rarely & 75.3 & 73.5 & & 74.1 & 74.7 & 74.4 \\
\hline Sometimes/often & 24.7 & 26.5 & & 25.9 & 25.3 & 25.6 \\
\hline \multicolumn{7}{|l|}{ CIGARETTE PACK DISPLAYS† } \\
\hline Large supermarkets & & & $=.018$ & & & $<.001$ \\
\hline Low & 35.6 & 30.2 & & 23.9 & 40.8 & 32.9 \\
\hline Med & 33.5 & 30.3 & & 36.8 & 27.8 & 31.9 \\
\hline High & 30.9 & 39.5 & & 39.3 & 31.5 & 35.1 \\
\hline Small supermarkets & & & $<.001$ & & & $<.001$ \\
\hline Low & 39.2 & 28.1 & & 25.6 & 40.8 & 33.7 \\
\hline Med & 36.4 & 32.4 & & 37.7 & 31.6 & 34.4 \\
\hline High & 24.4 & 39.6 & & 36.7 & 27.6 & 31.8 \\
\hline Convenience stores & & & $=.001$ & & & NS \\
\hline Low & 41.1 & 31.7 & & 34.5 & 38.2 & 36.5 \\
\hline Med & 38.7 & 39.4 & & 40.9 & 37.4 & 39.0 \\
\hline High & 20.3 & 28.9 & & 24.6 & 24.4 & 24.5 \\
\hline Petrol stations & & & NS & & & $=.014$ \\
\hline Low & 30.4 & 30.3 & & 28.0 & 32.4 & 30.4 \\
\hline Med & 33.7 & 32.9 & & 38.1 & 29.2 & 33.3 \\
\hline High & 35.9 & 36.8 & & 34.0 & 38.4 & 36.3 \\
\hline
\end{tabular}

† Level of exposure determined by combination of frequency visiting site and frequency seeing pack displays.

* Respondents aged 12-15 years excluded $(n=334)$ as not asked this question - younger age group 16-17 year-olds only.

\section{Discussion}

This study shows that adolescents and young adults in NSW are exposed to relatively high levels of tobacco advertising or promotion at the PoS, on the internet, in entertainment media and at venues such as events or festivals and pubs, clubs, nightclubs or bars, despite the restrictions on the marketing of tobacco in Australia.
The high levels of exposure particularly at the PoS and to people smoking cigarettes in movies and on TV found in this study highlight that the retail environment and entertainment media are important avenues for the industry to market tobacco and tobacco products.

Most adolescents and young adults were exposed to cigarette pack displays in stores in NSW, which provides 
Table 3 Adjusted odds ratios with $95 \%$ percent confidence intervals ${ }^{1}$ for participants reporting seeing forms of tobacco promotion sometimes/often in the last month

\begin{tabular}{|c|c|c|c|c|c|c|c|c|c|c|c|c|}
\hline \multirow[b]{2}{*}{$\begin{array}{l}\text { Predictor } \\
\text { (reference category) }\end{array}$} & \multicolumn{3}{|c|}{ Events/festivals } & \multicolumn{3}{|c|}{$\begin{array}{l}\text { Brands/companynames/ } \\
\text { logos on internet }\end{array}$} & \multicolumn{3}{|c|}{$\begin{array}{l}\text { People smoking in video } \\
\text { games }\end{array}$} & \multicolumn{3}{|c|}{$\begin{array}{l}\text { Cigarette pack displays } \\
\text { exposure all stores }\end{array}$} \\
\hline & OR & $95 \% \mathrm{Cl}$ & $\mathbf{p}^{3}$ & OR & $95 \% \mathrm{Cl}$ & $\mathbf{p}^{3}$ & OR & $95 \% \mathrm{Cl}$ & $p^{3}$ & OR & $95 \% \mathrm{Cl}$ & $\mathbf{p}^{2}$ \\
\hline Age $18-24$ years $(12-17)$ & 0.68 & $(0.46,1.01)$ & 0.055 & 0.46 & $(0.30,0.70)$ & 0.000 & 0.90 & $(0.59,1.38)$ & 0.626 & 0.61 & $(0.40,0.91)$ & 0.016 \\
\hline Sex (Male) & 1.32 & $(0.97,1.80)$ & 0.078 & 1.23 & $(0.88,1.70)$ & 0.219 & 0.28 & $(0.20,0.39)$ & $<.001$ & 1.58 & $(1.17,2.13)$ & 0.003 \\
\hline SES (not disadvantaged) & 0.95 & $(0.68,1.32)$ & 0.748 & 1.31 & $(0.92,1.85)$ & 0.134 & 1.01 & $(0.71,1.44)$ & 0.943 & 1.13 & $(0.82,1.56)$ & 0.437 \\
\hline Disposable income (none) & & & 0.354 & & & 0.298 & & & 0.976 & & & 0.947 \\
\hline$<=\$ 50$ & 1.52 & $(0.79,2.91)$ & 0.825 & 1.90 & $(0.87,4.11)$ & 0.420 & 0.82 & $(0.43,1.56)$ & 1.00 & 0.98 & $(0.5,1.90)$ & 1.00 \\
\hline$\$ 50-\$ 100$ & 1.10 & $(0.52,2.33)$ & 1.00 & 2.34 & $(1.01,5.42)$ & 0.188 & 0.80 & $(0.38,1.68)$ & 1.00 & 1.64 & $(0.78,3.45)$ & 1.00 \\
\hline$\$ 100+$ & 1.05 & $(0.50,2.20)$ & 1.00 & 1.72 & $(0.73,4.03)$ & 0.848 & 0.80 & $(0.39,1.64)$ & 1.00 & 1.60 & $(0.75,3.40)$ & 1.00 \\
\hline Unknown & 0.94 & $(0.32,2.75)$ & 1.00 & 1.26 & $(0.37,4.32)$ & 1.00 & 0.75 & $(0.23,2.46)$ & 1.00 & 1.06 & $(0.38,2.99)$ & 1.00 \\
\hline Ever smoked (never smoked) & 0.85 & $(0.58,1.27)$ & 0.435 & 0.64 & $(0.43,0.95)$ & 0.027 & 0.83 & $(0.55,1.23)$ & 0.345 & 1.27 & 7) & 0.232 \\
\hline Household smoking (none) & & & 0.457 & & & 0.701 & & & 0.646 & & & 0.303 \\
\hline 1 person & 1.26 & $(0.86,1.85)$ & 0.461 & 1.18 & $(0.8,1.75)$ & 0.818 & 0.84 & $(0.55,1.26)$ & 0.775 & 0.86 & $(0.59,1.25)$ & 0.474 \\
\hline $2+$ people & 0.99 & $(0.57,1.75)$ & 1.00 & 1.01 & $(0.55,1.85)$ & 1.00 & 0.85 & $(0.50,1.45)$ & 1.00 & 0.66 & $(0.38,1.15)$ & 1.00 \\
\hline Friends smoking (none) & & & 0.015 & & & 0.079 & & & 0.055 & & & 0.161 \\
\hline 1 friend & 1.98 & $(1.28,3.04)$ & 0.006 & 1.70 & $(1.09,2.00)$ & 0.059 & 1.18 & $(0.74,1.88)$ & 1.00 & 1.29 & $(0.85,1.97)$ & 0.403 \\
\hline 2 friends & 1.04 & $(0.63,1.74)$ & 1.00 & 1.50 & $(0.91,2.48)$ & 0.340 & 1.90 & $(1.16,3.11)$ & 0.031 & 1.26 & $(0.79,2.01)$ & 0.459 \\
\hline $3+$ friends & 1.28 & $(0.79,2.08)$ & 0.953 & 1.52 & $(0.92,2.49)$ & 0.302 & 1.58 & $(0.98,2.55)$ & 0.187 & 0.95 & $(0.59,1.52)$ & 0.101 \\
\hline Internet use (hours/day) & & - & - & 1.06 & $(0.99,1.15)$ & 0.11 & 1.08 & $(1.01,1.17)$ & 0.030 & - & - & - \\
\hline
\end{tabular}

${ }^{1}$ Full results shown only for models that reached statistical significance. Analyses also included seeing promotions or advertisements in pubs/clubs/nightclubs or bars, seeing people smoking in movies, in TV shows and on the internet, but the overall models did not reach statistical significance (>.05)

${ }^{2}$ High exposure for seeing cigarette pack displays defined as top quartile of scores for summed frequency of visit by frequency of seeing cigarette pack display across all store types

${ }^{3}$ Significance values for overall test shown for multicategory variables (e.g., disposable income), and multiple contrasts reported with Bonferroni adjustment

further justification for the introduction of the PoS display ban. It is interesting to note, however, that despite the first phase of the PoS display ban in NSW being implemented six months prior, most adolescents and young adults still report being exposed to cigarette pack displays in these stores. This raises the question of whether participants actually saw the displays, indicating non-compliance with legislation, or if they assumed that they had seen them because they had grown used to seeing the displays prior to Phase 1 .

Perceived exposure to people smoking cigarettes in movies and on TV was also found to be relatively high in this study and efforts to reduce exposure warrants attention in Australia. Although no association was found between exposure and smoking, other studies have shown how portrayals of smoking in films or movies can increase susceptibility to smoking [23].

Exposure to people smoking cigarettes in video games; tobacco brands, company names and logos on the internet; and promotions or advertising for cigarettes or other tobacco products at events or festivals, or in pubs, clubs, nightclubs or bars, while comparatively low, was still reasonably common. In particular, almost one-quarter of participants were using the internet for three or more hours each day, making the potential for exposure via this medium quite high. Whilst no studies to the authors' knowledge have assessed the impact of these forms of exposure on smoking-related cognitions and behaviours among adolescents and young adults, it is possible that exposure to smoking through these mediums may be undermining efforts to denormalise smoking.

This study demonstrates that adolescents in particular were at highest risk of exposure to 'below-the-line' means of tobacco advertising or promotion, and that tobacco industry marketing through the mediums studied are reaching this vulnerable population.

\section{Strengths and limitations}

Strengths of the TPIS are the large sample size, the representativeness of the sample, the inclusion of a large number socio-demographic measures and that fact that it is the only known study of its type in Australia monitoring exposure to tobacco promotion in 'below-theline' channels (at the PoS, on the internet and in entertainment media) among adolescents and young adults.

There are, however, some limitations. Firstly, the study relies on self-reported exposure not actual exposure to tobacco promotion. The measure of exposure to tobacco promotion across a variety of channels relied on retrospective recall, possibly resulting in some imprecision in measurement. Similarly, while the distinction between 
small and large chain grocery stores in the Australian context is generally very obvious, this may also have resulted in some imprecision in measurement. Secondly, the use of RDD sampling frame will have resulted in systematic exclusion of mobile phone-only households. However, this should not have overtly influenced the results as the proportion of mobile-phone only households in Australia is relatively small [41,42]. Finally, the results from this study may not be generalisable to adolescents and young adults from other jurisdictions given the potential differences in tobacco control legislation regarding promotion or marketing of tobacco.

\section{Conclusions}

Findings from this study highlight that 'below-the-line' means of tobacco promotion are being noticed by young people in NSW, with high levels of exposure at the PoS through cigarette pack displays and to portrayals of smoking in films or movies and TV shows.

Exposure to tobacco promotion through video games, the internet and events is also evident and of particular concern are the higher levels of exposure among adolescents aged 12-17 years. Public health authorities need to not only monitor these trends, but to address tobacco promotion in these forms through policy and practice.

\section{Acknowledgements}

We would like to acknowledge Anita Dessaix, Blythe O'Hara and Mayanne Lafontaine for their participation in the design and operation of the study. We would also like to acknowledge Paul Myers of the Social Research Centre for managing the fieldwork and conducting topline analysis, and Anne Jones and David Currow for their feedback on the draft manuscript.

\section{Author details}

${ }^{1}$ Cancer Institute NSW, Eveleigh, New South Wales, Australia. ${ }^{2}$ Sydney School of Public Health, University of Sydney, New South Wales, Australia.

\section{Authors' contributions}

DAP conceived of the study, participated in its design and coordination, oversaw the statistical analysis and drafted the manuscript. ACG conceived and performed the statistical analysis, led the interpretation of results and helped to draft the manuscript. CR advised on the statistical analysis, aided in the interpretation of results and helped to draft the manuscript. JK participated in the design of the study and helped to draft the manuscript. TC participated in the design of the study and helped to draft the manuscript. SD participated in the design of the study, advised on the statistical analysis and critically reviewed the manuscript. $A B$ advised on the statistical analysis, aided in the interpretation of results and critically reviewed the manuscript. All authors read and approved the final manuscript.

\section{Competing interests}

The authors declare that they have no competing interests.

Received: 22 December 2011 Accepted: 12 June 2012 Published: 12 June 2012

\section{References}

1. Lovato C, Linn G, Stead LF, Best A: Impact of tobacco advertising and promotion on increasing adolescent smoking behaviours. Cochrane Database Syst Rev 2011, CD003439, DOI: 10.1002/14651858.CD003439.pub2.
2. Wakefield M, Flay B, Nichter M, Giovino G: Effects of anti-smoking advertising on youth smoking: a review. J Health Commun 2003, 8:229-247

3. DiFranza JR, Wellman RJ, Sargent JD, Weitzman M, Hipple BJ, Winickoff JP: Tobacco promotion and the initiation of tobacco use: assessing the evidence for causality. Pediatrics 2006, 117:e1237-1248.

4. Paynter J, Edwards R: The impact of tobacco promotion at the point of sale: A systematic review. Nicotine and Tobacco Research 2009, 11:25-35.

5. Shafey O, Eriksen M, Ross H, Mackay J: In The Tobacco Atlas Edited by: Atlanta: American Cancer Society , 32009.

6. National Preventative Health Taskforce: Australia: the healthiest country by 2020. Technical Report No 2: Tobacco control in Australia: making smoking history. Including addendum for October 2008 to June 2009. Book Australia: the healthiest country by 2020. Technical Report No 2: Tobacco control in Australia: making smoking history. Including addendum for October 2008 to June 2009 Canberra: Commonwealth of Australia; 2009.

7. Tobacco in Australia: Facts and Issues. Edited by: Scollo M, Winstanley MH. Melbourne: Cancer Council Victoria; , 3 2008:[http://www. tobaccoinaustralia.org.au].

8. Harper TA, Martin JE: Under the radar-how the tobacco industry targets youth in Australia. Drug Alcohol Rev 2002, 21:387-392.

9. Carter SM: New frontier, new power: the retail environment in Australia's dark market. Tob Control 2003, 12(Suppl 3):iii95-iii101.

10. Carter SM: Going below the line: creating transportable brands for Australia's dark market. Tob Control 2003, 12(Suppl 3):iii87-94.

11. Schooler C, Feighery E, Flora JA: Seventh graders' self-reported exposure to cigarette marketing and its relationship to their smoking behavior. Am J Public Health 1996, 86:1216-1221.

12. MacFadyen L, Hastings $G$, MacKintosh A: Cross-sectional study of young people's awareness of and involvement with tobacco marketing. $\mathrm{Br}$ Med J 2001, 322:513.

13. Henriksen L, Feighery RN, Wang Y, Fortmann SP: Association of retail tobacco marketing with adolescent smoking. Am J Public Health 2004, 12:2081-2083.

14. Braverman MT, Aaro LE: Adolescent smoking and exposure to tobacco marketing under a tobacco advertising ban: findings from 2 Norwegian national samples. Am J Public Health 2004, 94:1230-1238.

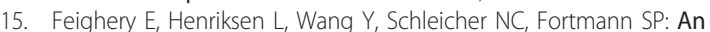
evaluation of four measures of adolescents' exposure to cigarette marketing in stores. Nicotine \& Tobacco Research 2006, 8:751-759.

16. Slater S, Chaloupka F, Wakefield M, Johnston LD, O'Malley PM: The impact of retail cigarette marketing practices on youth smoking uptake. Archives of Pediatric and Adolecent Medicine 2007, 161:440-445.

17. Weiss JS, Cen S, Schuster V, Unger JB, Anderson Johnson C, Mouttapa M, Schreiner WS, Boley Cruz T: Longitudinal effects of pro-tobacco and antitobacco messages on adolescent smoking susceptibility. Nicotine \& Tobacco Research 2006, 8:455-465.

18. Mackintosh AM, Moodie C, Hastings G: The Association Between Point-ofSale Displays and Youth Smoking Susceptibility. Nicotine \& Tobacco Research 2011, DOI: 10.1093/ntr/ntr1185.

19. Henriksen L, Flora JA, Feighery E, Fortmann SP: Effects on youth of exposure to retail tobacco advertising. Journal of Applied Social Psychology 2002, 32:1771-1789.

20. Wakefield M, Germain D, Durkin S, Henriksen L: An experimental study of effects on schoolchildren of exposure to point-of-sale cigarette advertising and pack displays. Health Educ Res 2006, 21:338-347.

21. Chapman S: What should be done about smoking in movies? Tob Control 2008, 17:363-367.

22. Lyons A, McNeill A, Chen Y, Britton J: Tobacco and tobacco branding in films most popular in the UK from 1989 to 2008. Thorax 2010, 65:417-422.

23. National Cancer Institute: The Role of the Media in Promoting and Reducing Tobacco Use. Book The Role of the Media in Promoting and Reducing Tobacco Use Bethseda, MD: U.S. Department of Health and Human Services, National Institutes of Health, National Cancer Institute; 2008.

24. Sargent JD, Stoolmiller M, Worth KA, Dal Cin S, Wills TA, Gibbons FX, Gerrard M, Tanski S: Exposure to smoking depictions in movies: its association with established adolescent smoking. Arch Pediatr Adolesc Med 2007, 161:849-856

25. Song AV, Ling PM, Neilands TB, Glantz SA: Smoking in movies and increased smoking among young adults. Am J Prev Med 2007, 33:396-403. 
26. Dalton MA, Beach ML, Adachi-Mejia AM, Longacre MR, Matzkin AL, Sargent JD, Heatherton TF, Titus-Ernstoff L: Early exposure to movie smoking predicts established smoking by older teens and young adults. Pediatrics 2009, 123:e551-558.

27. Hanewinkel R, Sargent JD: Exposure to smoking in internationally distributed American movies and youth smoking in Germany: a crosscultural cohort study. Pediatrics 2008, 121:e108-117.

28. Hunt $K$, Henderson M, Wight D, Sargent JD: Exposure to smoking in films and own smoking among Scottish adolescents: a cross-sectional study. Thorax 2011, 66:866-874.

29. Waylen AE, Leary SD, Ness AR, Tanski SE, Sargent JD: Cross-sectional association between smoking depictions in films and adolescent tobacco use nested in a British cohort study. Thorax 2011, 66:856-861.

30. Morgenstern M, Poelen EA, Scholte R, Karlsdottir S, Jonsson SH, Mathis F, Faggiano F, Florek E, Sweeting H, Hunt K, et al: Smoking in movies and adolescent smoking: cross-cultural study in six European countries. Thorax 2011, 66:875-883.

31. Ribisl KM: The potential of the internet as a medium to encourage and discourage youth tobacco use. Tob Control 2003, 12:i48-i59.

32. Hrywna $\mathrm{M}$, Delnevo $C D$, Lewis MJ: Adult recall of tobacco advertising on the Internet. Nicotine \& Tobacco Research 2007, 9:1103-1107.

33. Freeman B, Chapman S: British American Tobacco on Facebook: undermining Article 13 of the global World Health Organization Framework Convention on Tobacco Control. Tob Control 2010, DOl: 10.1136/tc.2009.032847.

34. American Association for Public Opinion Research: Standard definitions: final dispositions of case codes and outcome rates for surveys Lenexa, Kansas: AAPOR; 2008.

35. ITC Four Country Research Team: International Tobacco Control Policy Evaluation Survey (ITC): Four country project. Waves 2-8 technical report 2011 [http://www.itcproject.org/documents/keyfindings/ 4cw28techreportmay2011_2_pdf].

36. Australian Institute of Health \& Welfare: 2010 National Drug Strategy Household Survey report Canberra: AlHW; 2011 [http://www.aihw.gov.au/ publication-detail/?id = 32212254712].

37. Australian Bureau of Statistics: 2006 census of population and housing: Socioeconomic indexes for area's (SEIFA) Canberra, Australia: Commonwealth of Australia; 2008 [http://www.abs.gov.au/ausstats/abs@.nsf/mf/2033.0.55.001].

38. Pierce JP, Choi WS, Gilpin EA, Farkas AJ, Merritt RK: Validation of susceptibility as a predictor of which adolescents take up smoking in the United States. Health Psychol 1996, 15:355-361.

39. Australian Bureau of Statistics: Population by age and sex, Australian states and territories, June 2006 Canberra: Australian Bureau of Statistics; 2007 [http://www.abs.gov.au/Ausstats/abs@.nsf/mf/3201.0].

40. StataCorp: Stata Statistical Software: Release 11 College Station, TX: StataCorp LP; 2009.

41. Pennay DW, Bishop N: Profiling the 'mobile phone only' population: A study of Australians with a mobile phone and no landline telephone Melbourne: The Social Research Centre; 2009 [http://www.srcentre.com.au/Mobile\% 20Phone\%20Only\%20White\%20Paper\%20v4.pdf].

42. Australian Communications and Media Authority: Convergence and communications: Report 2: Australian household consumers' take-up and use of voice communications services Canberra: Commonwealth of Australia; 2010 [http://www.acma.gov.au/webwr/_assets/main/lib310665/ report_2_take_up_and_use_of_voice_comms.pdf].

\section{Pre-publication history}

The pre-publication history for this paper can be accessed here: http://www.biomedcentral.com/1471-2458/12/429/prepub

\section{doi:10.1186/1471-2458-12-429}

Cite this article as: Perez et al:: Tobacco promotion 'below-the-line':

Exposure among adolescents and young adults in NSW, Australia. BMC Public Health 2012 12:429.

\section{Submit your next manuscript to BioMed Central and take full advantage of:}

- Convenient online submission

- Thorough peer review

- No space constraints or color figure charges

- Immediate publication on acceptance

- Inclusion in PubMed, CAS, Scopus and Google Scholar

- Research which is freely available for redistribution

Submit your manuscript at www.biomedcentral.com/submit
Biomed Central 